\title{
US military accommodates astronomers
}

Washington. Astronomers have persuaded the US Pentagon's Strategic Defense Initiative (SDI) to change its plan to orbit a nuclear reactor that might have interfered with observations by astronomy satellites. Managers of the SDI project to orbit the reactor as a test of nuclear propulsion in space have agreed to do whatever is necessary to avoid compromising the scientific return from the satellites, even if it means paying for a more expensive rocket to lift the Topaz 2 reactor into a higher orbit.

Astronomers first became concerned about the Topaz mission last September, when they learned that the SDI office intended to place the Russian-built reactor into an orbit with an altitude of $1,600 \mathrm{~km}$. Similar reactors flown by the Soviets at lower altitudes in the $1980 \mathrm{~s}$ had interfered with two high-energy astronomy missions: Japan's Ginga X-ray satellite and the US Solar Maximum Mission satellite. The interference comes from two types of reactor emissions: fission gamma rays, which cloud the cosmic X-ray background, and secondary particles, which can give false readings when they strike sensitive detectors.

A launch is planned for 1995 , when as many as ten satellites observing in X-ray and gamma-ray wavelengths will be either in space or on the way to the launch pad. The mission most in jeopardy would be the National Aeronautics and Space Administration (NASA)'s \$617-million Compton Gamma Ray Observatory, launched in 1991. According to calculations done at the Naval Research Laboratory, the Compton satellite

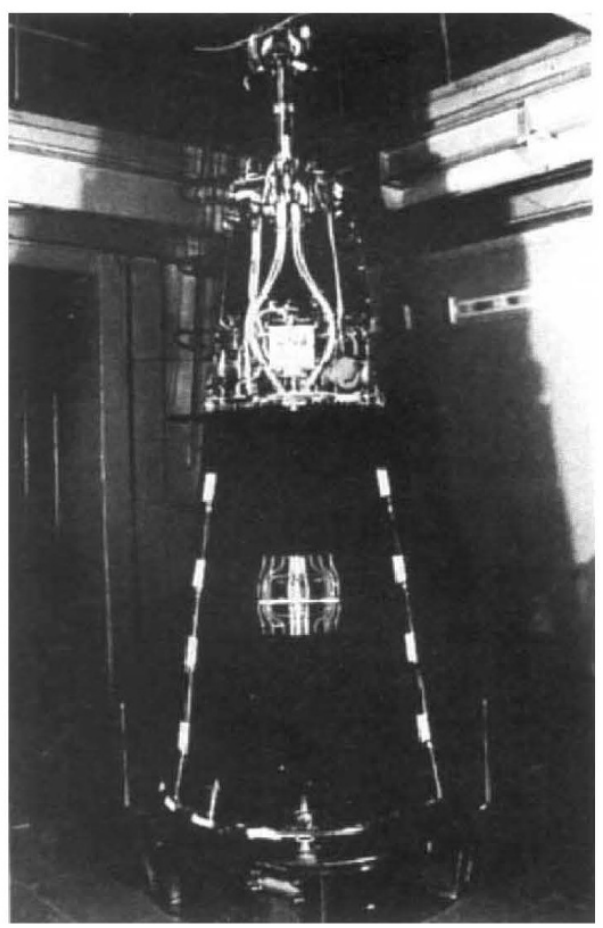

Topaz 2 reactor raises a ruckus. would get as many as 30 false readings a day if Topaz were placed in an initial orbit of $1,600 \mathrm{~km}$, and one of its instruments for detecting gamma-ray bursts would effectively be blinded.

Astronomers approached SDI with their concerns, and in October a NASA advisory panel requested that the reactor be placed in an orbit above $6,000 \mathrm{~km}$. At that distance, the Compton observatory would record one false event a day, thought to be a manageable level. But in December, after SDI appeared ready to solicit bids for a launch vehicle that could reach only a nominal $1,600-\mathrm{km}$ orbit, the astronomers launched their own media campaign.

That effort, led by Don Lamb of the University of Chicago, who chairs the highenergy astrophysics division within the American Astronomical Society (AAS), culminated in a resolution passed by the society at its annual meeting on 11 January, urging SDI to place the reactor in a higher orbit. A press release accompanying the resolution, timed to coincide with SDI's deadline for receiving launch bids for Topaz, led to coverage in the media. Two days later, managers of the \$150-million project were assuring scientists that the reactor would not be launched until it had met their requirements.
Both sides have remained civil throughout the controversy, commending the other side's willingness to search for a reasonable solution. The SDI office says that it was never committed to the $1,600-\mathrm{km}$ altitude, that non-interference with scientific missions is important and that there are some advantages to a higher orbit anyway. For their part, the astronomers say that it was all just a misunderstanding. "I think they [SDI officials] didn't realize how many satellites this would affect", says Peter Boyce, AAS's executive officer.

It is not known if a $6,000-\mathrm{km}$ altitude will solve the problem. More work is needed on predicting the effects of Topaz on astronomy satellites, an issue due to have been taken up earlier this week at a meeting involving US and Russian scientists at the University of Maryland. SDI believes that extra shielding may allow the reactor to be placed in a lower orbit without causing undue interference.

Meanwhile, both sides seem happy. The Pentagon can focus on what are expected to be more vociferous protests from anti-nuclear groups arising nearer to the launching of Topaz, while astronomers are pleased to have gotten their way. "It's the way you would like to be able to resolve problems", says Boyce.

Tony Reichhardt

\section{Healy, hundreds of others exit with Bush}

Washington. Any doubt that the Bush administration considered the directorship of the National Institutes of Health (NIH) to be a partisan post was removed last week when the White House informed its head, Bernadine Healy, and 650 other political appointees that they would be out of work after Bill Clinton's inauguration on 20 January as the country's forty-second president.

Letters declaring that their pro-forma resignations had been accepted were mailed on 13 January to every agency head serving "at the pleasure of the president", in other words, those appointed by George Bush for no fixed term and subject to confirmation by the US Senate. The sole survivor in science is the director of the National Science Foundation, Walter Massey, whose presidential appointment in 1991 extends for six years.

The action ends debate over whether Healy would be retained (see Nature 361, 2; 1993), as well as resolving the status of David Kessler, director of the Food and Drug Administration, and Daniel Goldin, director of the National Aeronautics and Space Administration. Both had hoped to hang onto their posts, but it is thought very unlikely that Clinton will choose to renominate them or any other Republican appointees, given the large number of Democrats bidding for the jobs.
The decision to fire everyone was made after the Bush and Clinton camps were unable to agree on the number of political appointees to be held over, and puts pressure on Clinton to announce his selections as quickly as possible. Traditionally, political appointees submit their resignations to the incoming president, leaving him to decide who stays and for how long.

NIH officials profess surprise, saying that Clinton transition officials had told them that Healy would be exempted from any political housecleaning. At the same time, no professional society or special interest group campaigned to retain the NIH director, as has been the case during previous transitions. Their silence attests to the widespread unhappiness in the biomedical community over Healy's 21 -month tenure, based on a belief that she ignored their interests while currying favour with her political bosses.

Speculation over her replacement is rampant but unrelated to the reality that the new president has more pressing business to attend to. But Bush's decision to end his political legacy with a stroke of the pen will doubtless increase the anxiety of researchers watching for the first tangible evidence of Clinton's attitude towards science.

Jeffrey Mervis 